\title{
Omeprazole and high dose ranitidine in the treatment of refractory reflux oesophagitis
}

S Cucchiara, R Minella, C Iervolino, M T Franco, A Campanozzi, M Franceschi, F D'Armiento, S Auricchio

\begin{abstract}
Thirty two consecutive patients (age range 6 months -13.4 years) with severe reflux oesophagitis were randomised to a therapeutic trial for eight weeks during which they received either standard doses of omeprazole (40 $\mathrm{mg} / \mathrm{day} / 1 \cdot 73 \mathrm{~m}^{2}$ surface area) or high doses of ranitidine (20 mg/kg/day). Twenty five patients completed the trial (12 on omeprazole, 13 on ranitidine). At entry and at the end of the trial patients underwent symptomatic score assessment, endoscopic and histological evaluation of the oesophagus, and simultaneous oesophageal and gastric pH measurement; results are given as median (range). Both therapeutic regimens were effective in decreasing clinical score (omeprazole before 24.0 (15-33), after 9.0 (0-18); ranitidine before 19.5 (12-33), after 9.0 (6-12)), in improving the histological degree of oesophagitis (omeprazole before $8 \cdot 0(6-10)$, after $2 \cdot 0(0-60)$; ranitidine before $8 \cdot 0(8-10)$, after $2 \cdot 0(2-6))$, and in reducing oesophageal acid exposure, measured as minutes of reflux at 24 hour pH monitoring (omeprazole before 129.4 (84-217), after $44.6(0 \cdot 16-128)$; ranitidine before $207 \cdot 3(66-306)$, after $58 \cdot 4$ (32-128)) as well as intragastric acidity, measured as median intragastric pH (omeprazole before $2 \cdot 1(1 \cdot 0-3 \cdot 0)$, after 5.1 (2.2-7.4); ranitidine before $1.9(1.6-4)$, after 3.4 $(2 \cdot 3-5 \cdot 3))$. Serum gastrin concentration was $>150 \mathrm{ng} / \mathrm{l}$ in four patients on omeprazole and in three patients on ranitidine. It is concluded that in children with refractory reflux oesophagitis high doses of ranitidine are comparable with omeprazole for the healing of oesophagitis and relief of symptoms; both drugs resulted in efficacious reduction of intragastric acidity and intraoesophageal acid exposure.

(Arch Dis Child 1993; 69: 655-659)
\end{abstract}

Gastro-oesophageal reflux (GOR) disease is a complex disorder with several pathogenetic components. ${ }^{12}$ Motility abnormalities such as lower oesophageal sphincter incompetence, defective oesophageal clearance, and delayed gastric emptying play a major part in the occurrence of reflux; however, gastric acid is crucial for the development and severity of oesophagitis, as well as for the clinical sequelae of the disease. ${ }^{3}$ The role of gastric acid secretion in the pathogenesis of GOR disease is emphasised by the fact that improved healing rates of oesophagitis are obtained through a powerful and sustained inhibition of gastric acid secretion induced by omeprazole, a substituted benzimidazole that inhibits the $\mathrm{H}^{+} / \mathrm{K}^{+}$ATPase enzyme of the gastric parietal cells. $^{4-7}$ Omeprazole has also resulted in mucosal healing in most patients with severe oesophagitis resistant to long term and/or high dose treatment with $\mathrm{H}_{2}$ receptor antagonists. ${ }^{8} 9$

It is generally agreed that GOR disease in childhood exhibits a more benign clinical course after medical treatment compared with adults. ${ }^{10}$ Nevertheless, severe reflux disease is common in children and can be responsible for significant morbidity and life threatening events ${ }^{11}$; furthermore, surgery is not uncommonly performed in children with persistent or intractable GOR disease. ${ }^{12}$

In this study we have compared omeprazole with ranitidine given at high doses in children with GOR disease resistant to traditional antisecretory treatment associated with prokinetics. We wished to evaluate the clinical efficacy and the effect on oesophagitis and on both oesophageal and gastric acidity of the two therapeutic regimens.

\section{Patients and methods}

Thirty two consecutive patients (age range 6 months-13.4 years; 16 boys and 16 girls) were enrolled in this study. These patients had previously received a diagnosis of GOR oesophagitis, based on 24 hour intraoesophageal $\mathrm{pH}$ monitoring and endoscopy with histology of the oesophageal mucosa. All had been unresponsive to an antireflux treatment including combined administration of ranitidine $(8 \mathrm{mg} / \mathrm{kg} /$ day, given in two doses) and cisapride $(0.8 \mathrm{mg} / \mathrm{kg} /$ day, given in three doses) for eight weeks. Unresponsiveness was defined as persistence of GOR symptoms and oesophagitis as detected by endoscopy and histology. None of the patients entering into the study had received combined treatment of cisapride and ranitidine for a period longer than eight weeks.

Before enrolment in the study, patients underwent symptomatic assessment, 24 hour intraoesophageal and intragastric $\mathrm{pH}$ measurement, and endoscopy of the oesophagus with biopsy. Patients were randomised to an eight week therapeutic trial of either omeprazole $\left(40 \mathrm{mg} /\right.$ day $/ 1.73 \mathrm{~m}^{2}$ surface area) given each morning or high doses of ranitidine $(20 \mathrm{mg} / \mathrm{kg} /$ day) morning and evening. Oesophageal strictures, systemic extraintestinal 
Table 1 Scoring system for symptoms of GOR disease

\begin{tabular}{lcc}
\hline Symptoms & Points & \\
\hline Vomiting and/or regurgitation & 0 & Absent (that is $<1$ ) \\
(No of days/week) & 3 & 1 \\
& 6 & $2-<5$ \\
& 9 & $\geqslant 5$ \\
Recurrent pneumonia and/or & 0 & None \\
asthma (No of episodes/2 & 6 & 1 \\
months $\times 6$ ) & 12 & 2 \\
& 18 & 3 \\
Anorexia or early satiety $(\%)^{\star}$ & 0 & $>75-100$ \\
& 3 & $>50-75$ \\
& 6 & $\geqslant 25-50$ \\
Pyrosis, chest pain, irritability & 9 & $<25$ \\
(No of days/week) & 0 & Absent (that is $<1$ ) \\
& 3 & $1-3$ \\
& 6 & $>3-<7$ \\
& 9 & $>7$
\end{tabular}

*Inability to finish a normal size meal, expressed as percentage of calories taken with meals in comparison with daily calorie requirement (over the week preceding the symptom evaluation).

diseases, and neurological disorders were excluded in all patients. Treatment was started within three days of the baseline endoscopy and $\mathrm{pH}$ study, which were performed by one of the authors who was unaware of the drug assignment and clinical follow up.

Symptoms were quantified at baseline and at the end of the trial by grading, on a weekly basis, GOR symptoms using a scale 0-3-6-9 (table 1). For this purpose, parents were instructed to record, on a diary card, frequency and severity of GOR symptoms. A physical examination was performed at each study visit. Blood and urine samples were collected at the entry and at the end of the trial. Haematological and biochemical analysis included complete blood cell count, erythrocyte sedimentation rate, serum creatinine, bilirubin, alkaline phosphatase, aspartate aminotransferase, alanine aminotransferase, serum electrolytes, and urinalysis. Fasting serum gastrin concentrations were obtained at baseline and at the end of the treatment.

Twenty four hour combined measurement of intraoesophageal and intragastric $\mathrm{pH}$ was performed with two flexible $\mathrm{pH}$ glass electrodes (Ingold M 1.5, Urdorf, Switzerland) passed through the naso-oesophageal route and positioned in the distal oesophagus and in the gastric corpus, respectively. The tip of the oesophageal electrode was located at the $87 \%$ of the distance between nares and lower oesophageal sphincter as determined according to Strobel's formula in patients under the age of 1 year. ${ }^{13}$ In subjects older than 1 year or over 1 metre in height the tip of the electrode was positioned fluoroscopically so that it laid over the third vertebral body above the diaphragm throughout the respiratory cycle. ${ }^{14}$ The tip of the intragastric electrode was located in the gastric corpus under fluoroscopy and was checked again the following day, at the end of the test. A silver/silver chloride reference electrode was applied to the chest skin. The measuring electrodes were carefully calibrated at the beginning and at the end of each study using commercially available standard buffer solutions $(\mathrm{pH} \quad 4 \cdot 0$ and $\mathrm{pH} \quad 7 \cdot 0$, Beckman); drift of the electrodes were accepted if less than $0.2 \mathrm{pH}$ units. GOR was defined whenever the distal oesophageal $\mathrm{pH}$ dropped to less than 4.0 for at least 20 seconds. The electrodes were connected with a portable battery operated recorder (Proxima 'Light', Synectics, Milan); data recorded were transferred to an IBM personal computer and analysed by Esophogram software $5 \cdot 4$ (Synectics, Milan).

The following intraoesophageal and intragastric $\mathrm{pH}$ parameters were measured: the time the oesophageal $\mathrm{pH}$ was $<4.0$ (oesophageal exposure acid time); intragastric median $\mathrm{pH}$; intragastric hydrogen activities $(\mathrm{mMol} / \mathrm{l})$ that were converted from the $\mathrm{pH}$ values using a standard table ${ }^{15}$; and the time the intragastric $\mathrm{pH}$ was less than 4.0 and $2 \cdot 0$. During the $\mathrm{pH}$ test patients were provided with standardised meals for their age. The meals were administered at a predetermined time for each patient. No beverages with $\mathrm{pH}$ below 4.0 were given and no food was allowed during the intervals between meals. All the $\mathrm{pH}$ studies were started at $8.00 \mathrm{am}$, after an overnight fast; all patients were requested to stop drugs affecting gastrointestinal motility and reducing gastric acid secretion for at least one week before the $\mathrm{pH}$ study. The oesophageal and gastric $\mathrm{pH}$ studies were performed at the beginning and at the end of the trial; the final $\mathrm{pH}$ study was done while patients were still receiving drugs.

Endoscopy of the oesophagus was performed with a paediatric fibreoptic endoscope (model GIFPQ20, Olympus, Torino) with a bioptic channel having $2.8 \mathrm{~mm}$ diameter. Two biopsy specimens were taken from the distal oesophageal mucosa, avoiding biopsies from the distal $20 \%$ of the oesophagus. Specimens were examined for the following features: basal cell zone hyperplasia, elongation of the papillae, ingrowth of vessels in the papillae, presence of intraepithelial eosinophils and/or neutrophils, and findings of mucosal erosions or ulcerations. Table 2 reports our scoring system for the histological criteria of oesophagitis. Histological specimens were examined with the aid of an ocular micrometer. During endoscopy oesophageal mucosa was observed for the presence of friability, granularity, erosions, and ulcerations. The latter, when present, were biopsied directly, even if located in the most distal oesophageal tract. The endoscopy was performed at baseline and within 48 hours of finishing the trial.

Results are given as median (range) values. The non-parametric tests were used for statistical analysis. A p value less than 0.05 was

Table 2 Scoring system for histological features of reflux oesophagitis

$$
\text { Features }
$$

Points

(A) Elongation of papillae, ${ }^{\star}$ thickening of basal cell 2 layert

(B) A+ingrowth of vessels in the papillae

(C) A,B +1-19 eosinophils and/or neutrophils on the most involved high power field

(D) $\mathrm{A}, \mathrm{B}+>20$ eosinophils and/or neutrophils on the 8 most involved high power field

(E) Findings of mucosal erosions and/or ulcerations. 10 Bleeding and slough of the mucosa

*Papillae elongated if their height, relative to the thickness of

the epithelium, was at least $>50 \%$.
tBasal cell hyperplasia if its thickness, related to the entire Hasal cell hyperplasia if its thickness, re
thickness of the epithelium, was $>25 \%$. 
Table 3 Median (range) intraoesophageal and intragastric $\mathrm{pH}$ variables before and after treatment in the two groups

\begin{tabular}{lcc}
\hline & Omeprazole & Ranitidine \\
\hline Before treatment & & \\
Time of oesophageal $\mathrm{pH}<4 \cdot 0(\mathrm{~min})$ & $129 \cdot 4(84-217)$ & $207 \cdot 3(66-306)$ \\
Median intragastric $\mathrm{pH}$ & $2 \cdot 1(1 \cdot 0-3 \cdot 0)$ & $1 \cdot 9(1 \cdot 6-4)$ \\
Intragastric hydrogen activity (mmol/) & $13.9(1 \cdot 2-100)$ & $12 \cdot 9(0 \cdot 1-25 \cdot 12)$ \\
Time of intragastric $\mathrm{pH}<4 \cdot 0(\mathrm{~min})$ & $1301(1065-1405)$ & $1150(1008-1388)$ \\
Time of intragastric $\mathrm{pH}<2 \cdot 0(\mathrm{~min})$ & $712(272-1167)$ & $807(396-1036)$ \\
& & \\
After treatment & $44 \cdot 6(0 \cdot 16-128)$ & $58 \cdot 4(32-128)^{\star \star}$ \\
Time of oesophageal $\mathrm{pH}<4 \cdot 0(\mathrm{~min})$ & $5 \cdot 1(2 \cdot 2-7 \cdot 4)^{\star}$ & $3 \cdot 4(2 \cdot 3-5 \cdot 3)^{\star \star}$ \\
Median intragastric $\mathrm{pH}$ & $1 \cdot 4(0 \cdot 01-6 \cdot 3)^{\star}$ & $1 \cdot 3(0 \cdot 01-5 \cdot 0)^{\star}$ \\
Intragastric hydrogen activity (mmol/) & $869(483-1167)^{\star \star}$ & $851(273-1127)^{\star \star}$ \\
Time of intragastric $\mathrm{pH}<4 \cdot 0(\mathrm{~min})$ & $290(17 \cdot 2-512)^{\star}$ & $330 \cdot 4(17 \cdot 2-535 \cdot 6)^{\star}$ \\
Time of intragastric $\mathrm{pH}<2 \cdot 0(\mathrm{~min})$ & & \\
\hline
\end{tabular}

${ }^{\star} \mathrm{p}<0.01,{ }^{\star \star} \mathrm{p}<0.05 v$ values before treatment.

considered as significant. The parents gave informed written consent and the protocol was approved by the ethics committee of the faculty.

\section{Results}

Of the 32 patients originally recruited for this study, 25 completed the trial and seven were unable to complete the study, three on ranitidine and four on omeprazole. Four of these patients were excluded as a result of noncompliance with the protocol, two were lost to the follow up, and one was withdrawn because of prolonged fever and upper respiratory infections. Thirteen patients received high doses of ranitidine and 12 had omeprazole. The two groups were comparable at baseline for severity of symptom score (omeprazole 24.0 (15-33); ranitidine 19.5 (12-33); not significant) and oesophagitis score (omeprazole 8.0 (6-10); ranitidine $8.0 \quad(8-10)$; not significant). Endoscopy showed in eight patients on omeprazole and in nine on high dose ranitidine erosions affecting the entire circumference of the distal oesophagus. In three patients on omeprazole and in three on ranitidine there were isolated rounded or linear erosions affecting the most distal oesophagus and not the entire circumference. In one patient on omeprazole and in one on ranitidine endoscopy showed oerythema and friability with spontaneous or contact bleeding. Intraoesophageal and intragastric $\mathrm{pH}$ variables were also similar in the two groups of patients (table 3 ). At the end of the trial both groups improved on the clinical score (omeprazole 9.0 (0-18), $\mathrm{p}<0.01$; ranitidine $9 \cdot 0(6-12), \mathrm{p}<0 \cdot 01)$. Marked symptom relief (decrease of symptom score $\geqslant 60 \%$ ) was observed in 10 patients on omeprazole and in nine patients on high doses of ranitidine. Both groups of patients had significant decrease in histological score compared with

Table 4 Median (range) percentage of improvement of intraoesophageal and intragastric $p H$ variables in the two groups

\begin{tabular}{lll}
\hline & Omeprazole & Ranitidine \\
\hline Time of oesophageal $\mathrm{pH}<4 \cdot 0$ & $61 \cdot 9(34-99)$ & $59 \cdot 6(2-83 \cdot 4)^{\star \star}$ \\
Time of intragastric $\mathrm{pH}<4 \cdot 0$ & $29 \cdot 0(16 \cdot 4-62 \cdot 8)$ & $22 \cdot 3(2 \cdot 1-72 \cdot 8)^{\star \star}$ \\
Time of intragastric $\mathrm{pH}<2 \cdot 0$ & $61 \cdot 5(7 \cdot 2-98 \cdot 4)$ & $62 \cdot 2(0 \cdot 35-95 \cdot 6)^{\star \star}$ \\
Median intragastric $\mathrm{pH}$ & $60 \cdot 1(9 \cdot 3-81)$ & $37 \cdot 4(0-56 \cdot 7)^{\star}$ \\
Intragastric hydrogen activities (mmol/) & $97 \cdot 9(20 \cdot 6-99 \cdot 9)$ & $91 \cdot 0(0-98 \cdot 7)^{\star \star}$
\end{tabular}

${ }^{\star} \mathrm{p}<0.05$ between omeprazole and ranitidine group.

$\star$ No statistical difference between the two groups. pretrial values (omeprazole $2.0(0-6), \mathrm{p}<0.01$; ranitidine $2.0(2-6), p<0.01)$. Healing of oesophagitis (return to grade 0 or grade 2 of histological score) occurred in nine patients on omeprazole and in eight patients on high doses of ranitidine.

Endoscopy after the trial revealed isolated small erosions affecting the distal oesophagus in three patients treated with omeprazole and in five patients on ranitidine; oerythema and oedema of distal oesophageal mucosa were observed in five patients on omeprazole and in six patients on ranitidine; oesophageal mucosa appeared normal in four patients treated with omeprazole and in two with ranitidine. Both therapeutic regimens decreased markedly oesophageal acid exposure time as well as intragastric acidity (table 3 ). Table 4 reports the percentage improvement of intraoesophageal and intragastric $\mathrm{pH}$ variables in the two treatment groups.

Three patients on ranitidine and four on omeprazole had fasting serum gastrin values $>150 \mathrm{ng} / \mathrm{l}$ at the end of the study. The highest reported serum gastrin concentration was 346 $\mathrm{ng} / \mathrm{l}$ for the omeprazole group and $482 \mathrm{ng} / \mathrm{l}$ for the ranitidine group. No serious adverse events to require discontinuing treatment and no abnormalities in the laboratory results were observed.

At the end of the trial drug treatment was stopped; however, if symptoms reappeared, patients were treated with courses of cisapride and ranitidine at conventional doses, as omeprazole or high dose ranitidine were not considered for long term treatment. At a six month follow up after the end of the trial, seven patients previously treated with omeprazole and five with high dose ranitidine were still symptomatic and showed both abnormal oesoph.ageal acid exposure at prolonged $\mathrm{pH}$ monitoring and oesophagitis at endoscopy (and histology); two of them underwent antireflux surgery.

\section{Discussion}

This study is the first controlled randomised trial comparing omeprazole with high doses of ranitidine in children with severe GOR disease, refractory to conventional treatment with $\mathrm{H}_{2}$ blockers and prokinetics. Omeprazole inhibits the final step in acid production, that is the enzyme $\mathrm{H}^{+} / \mathrm{K}^{+}$ATPase in the parietal cells. ${ }^{16}$ In several comparative studies in adults a clear superiority of omeprazole over standard doses of $\mathrm{H}_{2}$ blockers in healing oesophagitis and improving symptoms has been reported. ${ }^{17-22}$ The efficacy of omeprazole in healing peptic oesophagitis is also evident when the drug is compared with high doses of $\mathrm{H}_{2}$ antagonists. ${ }^{892324}$ This has been attributed to a more complete and long lasting suppression of gastric acid secretion induced by omeprazole as compared with the currently available $\mathrm{H}_{2}$ receptor blockers. ${ }^{1625}$ In our study the rate of oesophagitis healing and symptom relief induced by omeprazole was comparable with that observed with high dose ranitidine; furthermore, both therapeutic regimens produced similar rates of decrease in oesophageal acid 
exposure and intragastric acidity. However, omeprazole was more effective than high dose ranitidine in increasing intragastric median $\mathrm{pH}$; this might be due to a less sustained acid suppression by high dose ranitidine as compared to omeprazole in individual cases, but a partial lack of efficacy of ranitidine cannot be excluded. ${ }^{25}$ These results seem to confirm the common belief that refractoriness of GOR disease is mainly due to inadequate inhibition of gastric acid secretion with the currently recommended doses of $\mathrm{H}_{2}$ receptor blockers. ${ }^{26}$ On this purpose, a recent report in paediatric patients suggests that standard doses of $\mathrm{H}_{2}$ blockers might not be adequate for effective suppression of gastric acidity. ${ }^{27}$ Our results seem also to be at variance with those reported in adults, in whom a clear superiority of omeprazole over high dose ranitidine in improving symptoms and healing oesophagitis has been reported. ${ }^{16}$ This could be explained by the much higher dosage of ranitidine in this study than that used in previous trials in adult patients.

While omeprazole has widely been used in adults with a severe degree of oesophagitis, experience with the drug in children is very limited. In one report, three children with severe reflux oesophagitis (two with central nervous system disease), were successfully treated by omeprazole. ${ }^{28}$ Recently, 15 children with severe reflux disease, resistant to conventional treatment or high doses of ranitidine, were successfully treated with omeprazole administered for long term period (4-23 months); in these patients the dose of the drug was tailored on the basis of repeated 24 hour intraoesophageal $\mathrm{pH}$ monitoring. ${ }^{29}$

We assessed intragastric acidity by continuous intraluminal $\mathrm{pH}$ measurement of the stomach. ${ }^{30}$ This technique is useful for pharmacological and physiological studies of intragastric acidity in patients with upper gastrointestinal tract disease, provided that variables related to the method are standardised, that is type and localisation of the electrode, timing of feedings, and intervals between feeding. ${ }^{30} 31$ The method has previously been validated and has been shown to be as valid as gastric content sampling for measurement of acidity of the stomach. ${ }^{32}$

Treatment aimed at intensively suppressing gastric acid secretion in children with refractory oesophagitis might improve the long term course of the disease and avoid antireflux surgery. However, 12 of our patients were symptomatic six months after the end of the therapeutic trial with either omeprazole or high dose ranitidine and two needed antireflux surgery. Previous studies in adults have shown that short term treatment with omeprazole does not reduce the relapse rate of the disease. ${ }^{1633}$ This could be explained by return of the intragastric $\mathrm{pH}$ to pretreatment values or by failure of omeprazole administered for a short period to affect the motility abnormalities playing a part in the occurrence of reflux events, such as incompetence or transient relaxation of lower oesophageal sphincter and/or delayed gastric emptying. ${ }^{12}$ The tendency to recurrence of symptoms of almost half of our patients after stopping drugs might indicate the need for long term administration of omeprazole or high dose ranitidine (and other drugs such as prokinetics) as maintenance treatment for the prevention of complication and surgery.

Administration of omeprazole to humans results in increased plasma gastrin concentrations because of marked suppression of gastric acidity. ${ }^{34}$ However, this increase is significantly lower than that occurring after complete anacidity of the stomach, such as in pernicious anaemia or in the experimental condition of antrum exclusion. ${ }^{35} 36$ Furthermore, plasma gastrin concentrations after administration of omeprazole are lower and less sustained than those detected in classical hypergastrinaemic conditions such as Zollinger-Ellison syndrome. ${ }^{37}$ There is some concern about the hypergastrinaemia detected in patients treated chronically with omeprazole, was long term studies of toxicity in animals indicate that enterochromoaffin-like cell carcinoids can arise in rats exposed life long to omeprazole. ${ }^{38}$ Recent studies in man, however, indicate that omeprazole, given at the recommended doses, does not affect gastric oxyntic endocrine cells. ${ }^{39}$

In conclusion, children with severe reflux oesophagitis resistant to previous treatment with conventional doses of ranitidine, constitute a group that can be successfully treated with high doses of ranitidine or with omeprazole. Our study indicates that short term administration of omeprazole and high dose ranitidine are safe and effective. On the other hand, as the relapse rate of the disease seems to be unaffected by the drugs given for short period, some patients would require long term treatment. Data on long term administration of these drugs in children are very limited.

This paper has been presented in abstract form at the XXVI Annual Meeting of the European Society for Paediatric Gastroenterology and Nutrition, Gothenburg, Sweden, 27 June-1 July 1993.

This paper is dedicated to Professor Salvatore Auricchio on his sixtieth birthday.

1 Dent J. Recent views on the pathogenesis of gastrooesophageal reflux disease. Baillière's Clin Gastroenterol 1987; 1: 727-45.

2 Orenstein SR. Gastroesophageal reflux. Curr Probl Pediatr 1991; May-June: 193-241.

3 Orlando RC. Reflux esophagitis. In: Yamada T, Alpers DH, Uwyang C, Powell DW, Silverstein FE, eds. Textbook of gastroenterology. Philadelphia: Lippincott, 1991: 1123-47.

4 Bell NJV, Hunt RH. Role of gastric acid suppression in the treatment of gastro-oesophageal reflux disease. Gut 1992; 33: 118-24.

5 Ruth M, Enbom H, Lundell H, Lonroth H, Sandberg N, Sandmark S. The effect of omeprazole or ranitidine treatment on 24-hour oesophageal acidity in patients with reflux oesophagitis. Scand $\mathcal{f}$ Gastroenterol 1988; 23: 1141-6.

6 Dehn TCB, Shepherd HA, Colin-Jones D, Kettlewell MGW, Carroll NJH. Double blind comparison of omeprazole $(40 \mathrm{mg} \mathrm{od})$ verses cimetidine $(400 \mathrm{mg} \mathrm{qd})$ in the treatment of symptomatic erosive reflux oesophagitis, the treatment of symptomatic erosive reflux oesophagitis, monitoring. Gut 1990; 31: 509-13.

7 Bate CM, Keeling PWN, O'Morain C, et al. Comparison of omeprazole and cimetidine in reflux oesophagitis; symptomatic, endoscopic, and histological evaluation. Gut 1990, 31: 968-72.

8 Bardhan KD, Morris $\mathrm{P}$, Thompson $\mathrm{M}$, et al. Omeprazole in the treatment of erosive oesophagitis refractory to high dose cimetidine and ranitidine. Gut 1990; 31: 745-9.

9 Lundell L, Backman L, Ekstrom P, et al. Omeprazole or high-dose ranitidine in the treatment of patients with reflux oesophagitis not responding to standard doses of H2-receptor antagonist. Alimentation Pharmacology and Therapeutics 1990; 4: 145-56. 
10 Holloway RH, Orenstein SR. Gastro-oesophageal reflux disease in adults and children. Baillière's Clin Gastroenterol 1991; 5: 337-70.

11 Boyle JT. Gastroesophageal reflux in the pediatric patient. Gastroenterol Clin North Am 1989; 18: 315-37.

12 Folkaslrud EW, Foglia RP, Ament ME, Berqvist W, Vargas J. Operative treatment for the gastroesophageal reflux syndrome in children. $\mathcal{F}$ Pediatr Surg 1989; 24: 525-9.

13 Strobel CT, Byrne WJ, Ament ME, Euler AR. Correlation of oesophageal lengths in children with height: application to the Tuttle test without prior oesophageal manometry. f Pediatr 1979; 94: 81-4.

14 Working group of the European Society of Pediatric Gastroenterology and Nutrition. A standardized protocol for the methodology of esophageal $\mathrm{pH}$ monitoring and interpretation of the data for the diagnosis of gastrointerpretation of the data for the diagnosis of gastroesophageal

15 Moore EW. Determination of $\mathrm{pH}$ by the glass electrode: $\mathrm{ph}$ meter calibration for gastric analysis. Gastroenterology 1968; 54: 501-7.

16 Maton PN. Omeprazole. N Engl f Med 1991; 324: 965-75.

17 Klinkenberg-Knol EC, Jansen JBMJ, Festen HPM, Meuwissen SGM, Lamers CBHW. Double-blind multicentre comparison of omeprazole and ranitidine in the treatment of reflux esophagitis. Lancet 1987; i: 349-51.

18 Vantrappen G, Rutgeerts L, Schurmans P, Coenergrachts JL. Omeprazole $(40 \mathrm{mg})$ is superior to ranitidine in short$\mathrm{JL}$. Omeprazole $(40 \mathrm{mg})$ is superior to ranitidine in short-
term treatment of ulcerative reflux esophagitis. Dig Dis Sci term treatment of

19 Sandmark S, Carlsson R, Fausa O, Lundell L. Omeprazole or ranitidine in the treatment of reflux oesophagitis: results of a double-blind, randomized, Scandinavian multicenter study. Scand f Gastroenterol 1988; 23: 625-32.

20 Havelund T, Laursen LS, Skoubo-Kristensen E, et al. Omeprazole and ranitidine in treatment of reflux esophagitis: double blind comparative trial. $B M F$ 1988; 296: 89-92.

21 Zeitoun P, Rampal P, Barbier P, et al. Omeprazole (20 mg daily) compared to ranitidine ( $150 \mathrm{mg}$ twice daily) in the treatment of esophagitis caused by reflux: results of a double blind randomized multicenter trial in France and Belgium. Gastroenterol Clin Biol 1989; 13: 457-62.

22 Hetzel DJ, Bonnin M. Long-term management of hemorrhagic oesophagitis with cimetidine and omeprazole. Aust $N Z \mathcal{F}$ Med 1986; 16: 226-8.

23 Brunner G, Creutzfeldt W, Harke U, Lamberts R. Therapy with omeprazole in patients with peptic ulceration resiswith omeprazole in patients with peptic ulceration resistant to extended

24 Brunner G, Creutzfeldt W. Omeprazole in the long-term management of patients with acid-related diseases resistant to ranitidine. Scand $\mathcal{F}$ Gastroenterol Suppl 1989; 166: 101-5.
25 Lind T, Cederberg C, Idstrom JP, et al. 24-hour intragastric acidity and plasma gastrin during long-term treatment with omeprazole or ranitidine in patients with reflux esophagitis. Scand 7 Gastroenterol 1991; 26: 620-6.

26 Collen MJ, Lewis JH, Benjamin SB. Gastric acid hypersecretion in refractory gastroesophageal reflux disease. Gastroenterology 1990; 98: 654-61.

27 Lambert J, Mobassaleh M, Grand RJ. Efficacy of cimetidine for gastric acid suppression in pediatric patient. $\mathcal{F}$ Pediatr 1992; 120: 474-8.

28 Nelis GR, Westerveld BD. Treatment of resistant reflux oesophagitis in children with omeprazole. European fournal of Gastroenterology and Hepatology 1990; 2: 215-7.

29 Karioo M, Kane RE. Omeprazole treatment in children with peptic esophagitis refractory to ranitidine. Gastroenterology 1992; 102: A93.

30 Armstrong D, Emde C, Blum AL. Twenty-four-hour intragastric pH-metry studies: easy to do but difficult to
analyse. European fournal of Gastroenterology and analyse. European fournal

31 Merki HS, Witzel L, Walt RP, et al. Day-to-day variation of 24-hour intragastric acidity. Gastroenterology 1988; 94: 887-91.

32 Fimmel CJ, Etienne A, Cilluffo T, et al. Long-term ambulatory gastric $\mathrm{pH}$ monitoring: validation of a new method and effect of $\mathrm{H} 2$-antagonists. Gastroenterology 1985; 88: $1842-51$.

33 Hetzel DJ, Dent J, Reed WD, et al. Healing and relapse of severe peptic esophagitis after treatment with omeprazole. severe peptic esophagitis after treat

34 Lind T, Cederberg C, Olausson M, Olbe L. 24-hour intragastric acidity and plasma gastrin after omeprazole treatment and after proximal gastric vagotomy in duodenal ulcer patients. Gastroenterology 1990; 99: 1593-8.

35 Lanzon-Miller S, Pounder RE, Hamilton MR, et al. Twenty-four-hour intragastric acidity and plasma gastrin concentration in healthy subjects and patients with duodenal or gastric ulcer, or pernicious anaemia. Alimentation Pharmacology and Therapeutics 1987; 1: 225-37.

36 Alumets J, El Munshid HA, Hakansson R, et al. Effect of antum exclusion on endocrine cells of rat stomach. antrum exclusion on endocrine (Lond) 1979; 286: 145-55.

37 Jansen JBMJ, Klinkenberg-Knol EC, Meuwissen SGM, et al. Effect of long-term treatment with omeprazole on serum gastrin and serum group $\mathrm{A}$ and $\mathrm{C}$ pepsinogens in patients with reflux esophagitis. Gastroenterology 1990; 99: 621-8.

38 Larsson H, Hakanson R, Mattsson H, Ryberg B, Sundler F, Carlsson E. Omeprazole: its influence on gastric acid secretion, gastrin and ECL cells. Toxicol Pathol 1988; 16: 267-72.

39 Berlin RG. Omeprazole. Gastrin and gastric endocrine cell data from clinical studies. Dig Dis Sci 1991; 36: 129-36. 